\title{
INOVASI LEMBAR KERJA BERBASIS VEE MAPPING PADA PENDIDIKAN BIOLOGI ABAD 21
}

\author{
Ekawati $^{1}$, Andi Maulana ${ }^{1}$, Ahmad Ali ${ }^{1 *}$, Misykat Malik Ibrahim ${ }^{1}$, Ainul Uyuni Taufiq ${ }^{1}$, \\ Ilmi Zajuli Ichsan' ${ }^{2}$, Diana Vivanti Sigit ${ }^{2}$, Rita Istiana ${ }^{3}$, Titin ${ }^{4}$ \\ ${ }^{1}$ Pendidikan Biologi, Universitas Islam Negeri Alauddin Makassar, Indonesia \\ ${ }^{2}$ Pendidikan Biologi, Universitas Negeri Jakarta, Indonesia \\ ${ }^{3}$ Pendidikan Biologi, Universitas Pakuan, Indonesia \\ ${ }^{4}$ Pendidikan Biologi, Universitas Tanjungpura, Indonesia \\ *Corresponding Author: ahmad.ali@uin-alauddin.ac.id
}

\section{Article History}

Received : April 04 ${ }^{\text {th }}, 2021$

Revised : April 23 $3^{\text {th }}, 2021$

Accepted : May $05^{\text {th }}, 2021$

Published : May $20^{\text {th }}, 2021$

\begin{abstract}
Abstrak: Pembelajaran abad 21 menuntut keterampilan berpikir tingkat tinggi meliputi 4Cs (critical thinking, communication, collaboration, and creativity) sehingga dibutuhkan inovasi pembelajaran salah satunya dengan inovasi LKPD. Tujuan penelitian adalah mengembangkan LKPD berbasis Vee Mapping pada materi sistem pernapasan yang valid dan praktis sebagai bentuk inovasi Pendidikan biologi. Penelitian ini menggunakan metode penelitian research and development dengan model pengembangan 4D. Produk yang dikembangkan pada penelitian ini berupa LKPD berbasis Vee Mapping pada materi sistem pernapasan dengan menggunakan teknik pengumpulan data berupa kajian literatur, uji kevalidan dan uji kepraktisan. Instrumen pada penelitian ini berupa lembar validasi untuk mengukur tingkat kevalidan dan angket untuk melihat tingkat kepraktisan produk. Subjek penelitian ini adalah peserta didik sebanyak 12 orang. Hasil pada penelitian ini menunjukkan bahwa LKPD berbasis Vee Mapping pada materi sistem pernapasan yang dikembangkan memiliki tingkat validitas dengan skor 3,86 dan tingkat kepraktisan yaitu 3,51 dan termasuk dalam kategori sangat valid dan praktis sehingga layak untuk digunakan. Implikasi penelitian ini yaitu, LKPD berbasis Vee Mapping layak digunakan sebagai salah satu media yang dapat digunakan dalam pembelajaran biologi khususnya pada materi sistem pernapasan.
\end{abstract}

Kata kunci: lembar kerja, pengembangan Vee Mapping

\section{PENDAHULUAN}

Pendidikan pada dasarnya sangatlah sulit untuk dipisahkan dengan kehidupan manusia karena merupakan kebutuhan manusia agar menghasilkan sumber daya manusia yang berkualitas (Permana \& Chamisijatin, 2019). Proses pendidikan ini dilakukan untuk mempersiapkan manusia agar dapat hidup layak di masa depan dan untuk membekali manusia untuk bekerja praktis di era modern. Suatu pendidikan dapat dikatakan berkualitas apabila pendidikan tersebut dapat dijadikan sebagai jawaban dari segala pertanyaan dan tantangan yang muncul, diantaranya adalah ketersediaan media pembelajaran yang digunakan dalam proses pembalajaran (Sukiniarti, 2016). Dalam Proses pembelajaran seorang pendidik harus mampu merancang pembelajaran yang berpusat kepada peserta didik agar dapat mendorong motivasi, kreativitas, kemandirian dan minat belajar dengan pendekatan yang saintifik.
Terlibatnya peserta didik secara langsung dan aktif dalam proses pembelajaran memberikan gambaran terjadinya pembelajaran yang optimal (Buzov, 2014). Hal ini membuat seorang pendidik harus mampu menyusun media yang menarik, inovatif, variatif, kontekstual, dan tentunya sesuai dengan kebutuhan peserta didik khususnya dalam pembelajaran biologi (Nugraini et al., 2013).

Penggunaan media pembelajaran dilakukan dengan tujuan agar peserta didik lebih memahami serta lebih memaknai sebuah ilmu agar ilmu tersebut dapat bertahan lama dalam ingatan mereka (Nugraini et al., 2013). Media pembelajaran diperlukan dalam pembelajaran yang berguna sebagai wahana atau alat agar pesan yang terdapat dalam pembelajaran dapat tersampaikan ke peserta didik (Ross, 2017). Untuk menunjang proses pembelajaran biologi diperlukanlah media pembelajaran. Salah satunya adalah lembar kerja peserta didik (LKPD). LKPD mengaktifkan peserta didik, 
sebagai bahan ajar yang kaya tugas yang harus dikerjakan dan untuk berlatih dan meringkas, mampu membantu peserta didik agar lebih memahami materi yang diberikan dan memudahkan proses pelaksanaan pengajaran pada peserta didik (Cubukcu, 2008; Hemmerich et al., 2015; Oncu, 2016; Utami et al., 2016). LKPD merupakan lembaran-lembaran yang berisi pedoman pembelajaran dan tugas yang harus dikerjakan dan diselesaikan pada materi tertentu yang kontekstual (Paristiowati et al., 2019).

Berdasarkan hasil observasi yang dilakukan oleh peneliti pada tanggal 11 januari 2020 di SMA Negeri 1 Takalar didapatkan informasi bahwa dalam proses belajar mengajar biologi dalam kelas selama ini masih kurang mengaktifkan peserta didik dan lebih berpusat ke guru. Selain itu, LKPD yang digunakan dalam pembelajaran hanya berupa penyelesaian soalsoal pada LKPD tanpa didahului kegiatan identifikasi masalah. Hal ini penting mengingat pelajaran biologi bukan hanya sekumpulan konsep dan teori saja, tetapi dibutuhkan pengalaman belajar dalam prosesnya. LKPD berbasis Vee Mapping yang dikembangkan peneliti diharapkan agar peserta didik mampu menumbuhkan motivasi belajar dan minat belajar peserta didik, dimana peserta didik tidak hanya berfokus terhadap bagaimana iya mampu menguasai teori saja tapi peserta didik juga dapat melihat langsung melalui percobaan atau eksperimen sehingga pengetahuan yang didapatkan peserta didik dapat bertahan dalam jangka waktu yang lama.

Vee Mapping merupakan suatu alat yang menganalisis pemanfaatan $\mathrm{V}$ diagram yang dikembangkan oleh Gowin \& Alvarez (2005) yang berguna bagi peserta didik untuk memberikan bukti hubungan yang dapat peserta didik temukan antara teori dan praktek. Vee Mapping mempunyai dua sisi sebelah kiri sisi konseptual (berfikir) dan sebelah kanan sisi metodologis (bekerja), dimana kedua sisi tersebut masing-masing memiliki keterkaitan untuk menjawab pertanyaan fokus dan memberikan gambaran peristiwa saat praktikum. Pendidikan Biologi abad 21 mendorong siswa untuk bisa merealisasikan berbagai konsep yang ada di buku untuk diimplementasikan dalam kehidupan sehari-hari (Martin \& Betrus, 2019; Murphy et al., 2013; Tajudin \& Chinnappan, 2016). Berdasarkan uraian tersebut maka tujuan dari penelitian ini adalah untuk mengembangkan LKPD berbasis Vee mapping.

\section{METODE}

Penelitian ini merupakan jenis penelitian research and development dengan model pengembangan 4D oleh Thiagarajan dan Semmel yang terdiri atas 4 tahap yaitu define, design, develop dan disseminate (Thiagarajan et al., 1974). Namun pada penelitian ini hanya dilakukan sampai tahap develop (pengembangan) saja, sedangkan untuk tahap penyebaran (disseminate) tidak dilakukan karena adanya dampak dari Covid 19 yang menyebabkan adanya keterbatasan dalam penelitian ini. Lokasi penelitian di SMA Negeri 1 Takalar Jalan Tikkola Dg.Leo, Pattalassang, Kab. Takalar. Subjek pada penelitian ini adalah peserta didik berjumlah 12 orang. Produk yang dihasilkan pada penelitian ini berupa LKPD Berbasis Vee Mapping pada materi sistem pernapasan.

Instrumen yang digunakan pada penelitian ini berupa lembar validasi dan angket. Lembar validasi yang digunakan tersebut bertujuan untuk mengukur tingkat kepraktisan dan kevalidan dari produk. Instrumen ini menggunakan skala likert dengan 4 pilihan yaitu setuju, sangat setuju, tidak setuju dan sangat tidak setuju. Data yang didapatkan selanjutnya oleh peneliti akan dianalisis. Kriteria tingkat kevalidan dan tingkat kepraktisan LKPD berbasis Vee Mapping dapat dilihat pada tabel 1 dan tabel 2. Data dianalisis untuk menentukan kevalidan dan kepraktisan dengan krtiteria berikut:

Tabel 1 Kriteria Kevalidan

\begin{tabular}{ll}
\hline Nilai & Kriteria \\
\hline $3,5 \leq M \leq 4$ & Sangat valid \\
$2,5 \leq M<3,5$ & Valid \\
$1,2 \leq M<2,5$ & Cukup valid \\
$0 \leq M<1,5$ & Tidak valid \\
\hline Tabel 2 Kriteria kepraktisan & \\
\hline Nilai & Kriteria \\
\hline $3,6 \leq X i \leq 4$ & Sangat Praktis \\
$2,6 \leq X i \leq 3,5$ & Praktis \\
$1,6 \leq X i \leq 2,5$ & Cukup Praktis \\
$0 \leq X i \leq 1,5$ & Tidak Praktis \\
\hline
\end{tabular}

Penggunaan kriteria dapat memutuskan atau menyatakan produk yang dikembangkan memiliki derajat validitas yang memadai dinama nilai rata-rata validitas untuk setiap aspek penilaian minimal berada pada kategori valid dan nilai validitas keseluruhan aspek minimal masuk dalam kategori cukup valid. 


\section{HASIL DAN PEMBAHASAN}

Pengembangan LKPD berbasis Vee Mapping ini diadaptasi berdasarkan model 4-D yang terdiri dari 4 tahap yaitu define (pendefinisian), design (perancangan), develop (pengembangan) dan dissiminate (penyebaran). Namun pada penelitian ini hanya dilakukan sampai tahap pengembangan saja tanpa adanya tahap penyebaran (dissiminate) karena adanya pandemic covid 19 Covid 19 yang menyebabkan adanya keterbatasan peneliti untuk melakukan uji di lapangan. LKPD berbasis Vee Mapping yang dikembangkan telah divalidasi oleh validator ahli. Hasil analisis data dan deskripsi dari pengembangan yang dilakukan diuraikan sebagai berikut.

\section{Tahap pendefinisian (Define)}

Tujuan dari tahap ini yaitu menetapkan dan mendefinisikan syarat-syarat pembelajaran yang diawali dengan menganalisis tujuan pembatasan materi pada LKPD berbasis Vee Mapping yang dikembangkan. Terdapat beberapa langkah yang dilakukan pada tahap ini yaitu analisis awal-akhir, analisis peserta didik, analisis materi, analisis konsep dan analisis tujuan. Analisis awal-akhir bertujuan untuk mengetahui menemukan masalah-masalah yang dihadapi guru dan peserta didik pada sekolah tempat penelitian dalam proses pembelajaran. Analisis peserta didik dilakukan untuk mengetahui karakteristik dari peserta didik agar produk yang dibuat oleh peneliti memenuhi dan sesuai dengan kebutuhan peserta didik. Analisis materi dilakukan untuk menentukan isi materi pada LKPD yang dikembangkan. Analisis konsep dilakukan untuk mengetahui konsep yang sesuai dengan produk yang dikembangkan. Analisis tujuan dilakukan agar peneliti tidak menyimpang dari materi dan syarat-syarat yang telah ditetapkan.

\section{Tahap perancangan (Design)}

Tujuan dari tahap ini adalah merancang produk LKPD yang akan dikembangkan yang kemudian akan menjadi prototype I. Tahap perancangan terdiri dari beberapa langkah yaitu pemilihan media, pemilihan format dan rancangan awal produk. Pemilihan media dilakukan untuk menentukan media apa yang sesuai dengan kebutuhan peserta didik, media tersebut berupa LKPD berbasis Vee Mapping. Langkah selanjutnya yaitu pemilihan format, dilakukan untuk menentukan format apa yang dipakai dalam pengembangan LKPD. Langkah yang terakhir yaitu rancangan awal produk, dimana dilakukan rancangan awal mengenai produk yang akan dikembangkan. Lembar Kerja Peserta Didik dirancang untuk 3 kali pertemuan. LKPD dirancang dalam bentuk berbagai macam kegiatan yang akan dikerjakan oleh peserta didik secara berkelompok. Selain mengacu pada format penyusunan LKPD, peneliti juga menekankan pada berbasis Vee Mapping yang meliputi 5 tahap yaitu orientasi masalah, pengungkapan masalah, Pengungkapan pertanyaan fokus, Pengkonstruksian pengetahuan baru, dan evaluasi. LKPD juga berisi materi terkait sistem pernapasan dan pertanyaan-pertanyaan tentang sistem pernapasan.

\section{Tahap pengembangan (Develop)}

Tahap ini dilakukan dengan membuat produk LKPD berbasis Vee Mapping sesuai pada rancangan awal. Produk yang telah dibuat disebut prototype 1 kemudian divalidasi oleh validator yang ahli pada bidang pendidikan biologi. Dari hasil penilaian validator diperoleh saran dan masukan yang dijadikan dasar untuk merevisi produk. Produk hasil revisi disebut prototipe 2. Perbedaan hasil antara prototipe 1 dan prototipe 2 dapat dilihat pada tabel 3 berikut: 
Tabel 3 Perbedaan Prototipe 1 dan Prototipe 2

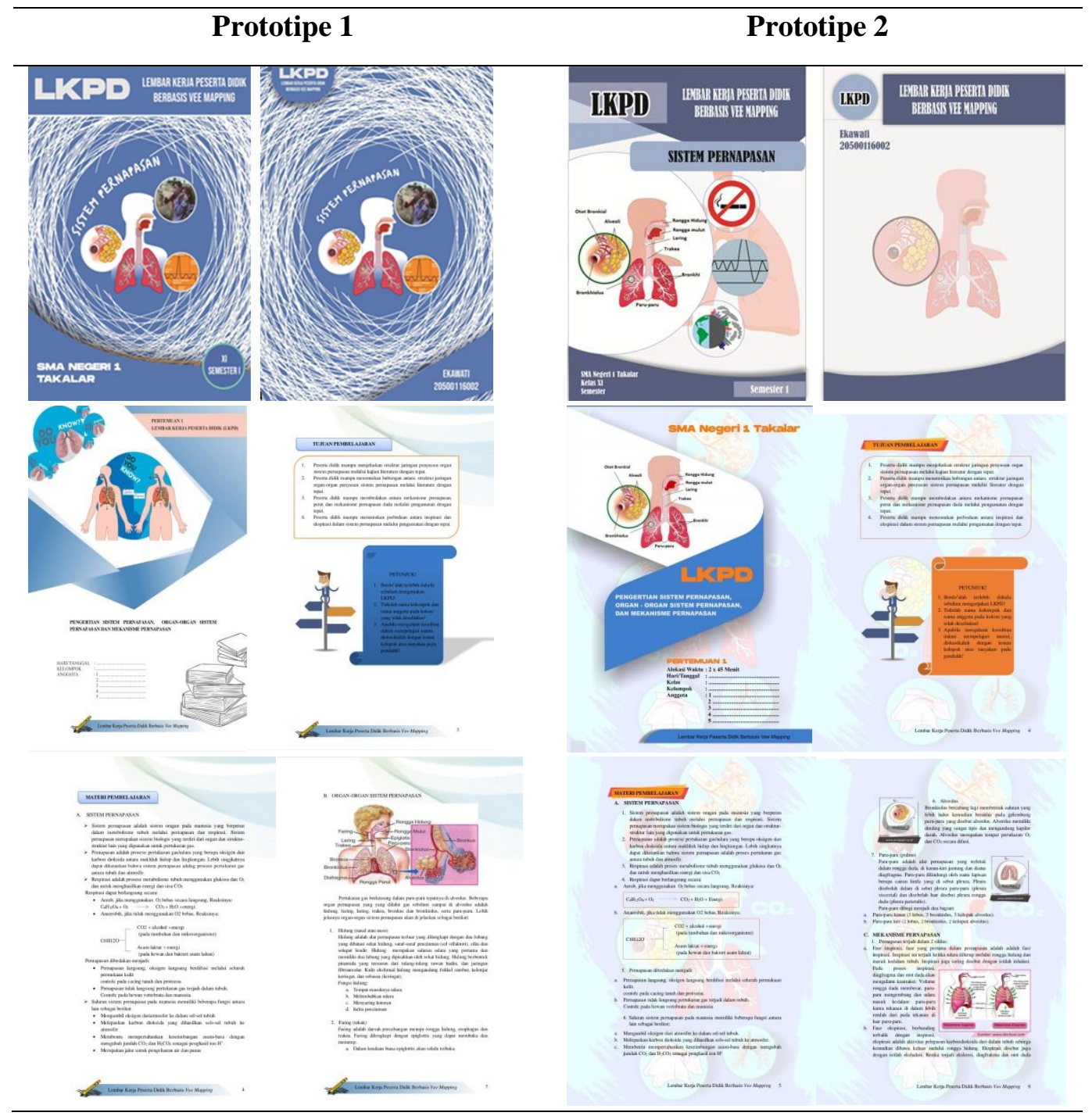

Adapun saran-saran dan masukan dari validator I dan validator II yaitu, perbaiki penulisan pada LKPD yang dibuat, tujuan pembelajaran disesuaikan dengan soal yang dibuat, tujuan pembelajaran harus sesuai dengan indikator, tambahkan nilai estetika pada LKPD yang dibuat agar lebih menarik, perbaiki halaman pada LKPD, menyesuaikan LKPD yang dibuat dengan komponen-komponen yang harus dimiliki oleh LKPD, tambahkan sumber, beri kotak pada setiap gambar yang ada dalam LKPD dan perhatikan tanda baca serta miringkan setiap kata yang menggunakan bahasa asing. Berdasarkan saran perbaikan yang diberikan oleh kedua validator, kemudian prototipe 1 diperbaiki sesuai dengan saran yang diberikan oleh kedua validator. Adapun Hasil penilaian validator terhadap LKPD berbasis Vee Mapping dapat dilihat pada tabel 4 berikut:

Tabel 4 Hasil Rata-rata Penilaian Validator

\begin{tabular}{lcl}
\hline Aspek yang dinilai & Skor & Kategori \\
\hline Format & 3.61 & Sangat Valid \\
Bahasa & 3.75 & Sangat Valid \\
Isi & 3.38 & Sangat Valid \\
Waktu & 3.58 & Sangat Valid \\
Manfaat/Kegunaan & 3.75 & Sangat Valid \\
Komponen Vee & 3,91 & Sangat Valid \\
Mapping & & \\
Rata-rata & 3,86 & Sangat Valid \\
\hline
\end{tabular}

Berdasarkan tabel 4 rata-rata hasil penilaian validator terhadap LKPD berbasis Vee 
Mapping yang dikembangkan yaitu 3,86 yang berada pada kategori sangat valid sehingga disimpulkan bahwa LKPD berbasis Vee Mapping dapat digunakan dengan sedikit revisi. Terdapat beberapa aspek yang perlu diperhatikan ketika validasi di antaranya yaitu konstruksi materi/isi, bahasa yang digunakan, kelengkapan/teknik penyajian, keterpaduan dan manfaat/kegunaan sesuai yang dikutip dari Badan Standar Nasional Pendidikan (2014).

\section{Kepraktisan}

Kepraktisan LKPD berbasis Vee Mapping ditentukan berdasarkan hasil analisis angket respon guru dan angket respon peserta didik yang berisikan pernyataan untuk mengetahui tanggapan terhadap LKPD yang dikembangkan oleh peneliti. Adapun hasil angket respon dapat dilihat pada tabel 5 .

Tabel 5 Hasil Angket Respon Peserta Didik dan Angket Respon Guru

\begin{tabular}{ll}
\hline Jenis Penilaian & Rata-rata \\
\hline Respon Guru & 3.72 \\
Respon Peserta Didik & 3.3 \\
Rata-rata Total & 3.51 \\
Kriteria Penilaian & Praktis \\
\hline
\end{tabular}

Berdasarkan tabel 5, diketahui bahwa LKPD berbasis Vee Mapping yang dikembangkan berapa pada kategori sangat praktis dengan rata-rata respon Guru 3,72 dan praktis menurut peserta didik dengan rata-rata 3,3. Keseluruhan aspek LKPD dinyatakan praktis dengan rata-rata 3,51. Hal ini berarti responden baik guru maupun peserta didik memberikan respon yang positif terhadap produk LKPD berbasis Vee Mapping yang telah dikembangkan.

\section{Tahap penyebaran (Disseminate)}

Tahap keempat yaitu tahap penyebaran. Pada penelitian ini tidak dilaksanakan tahap penyebaran dikarenakan adanya pandemi COVID 19 yang tidak memungkinkan peneliti melakukan tahap penyebaran

Kelebihan LKPD berbasis Vee Mapping ini dapat menjadikan peserta didik lebih aktif dalam pembelajaran. Hal tersebut disebabkan adanya kegiatan-kegiatan yang terdapat di dalam LKPD yang harus dilakukan oleh peserta didik, selain itu peserta didik tidak hanya belajar dalam kegiatan diskusi melainkan juga melakukan metode praktikum. Vee Mapping merupakan alat yang berguna bagi peserta didik untuk memberikan bukti hubungan yang dapat mereka buat antara teori dan praktek.

Inovasi pengembangan media pembelajaran ini merupakan sebuah bentuk inovasi dalam pendidikan biologi. Hal ini dikarenakan pada abad 21 siswa diharuskan untuk memiliki kemampuan yaitu berkolaborasi, berkomunikasi, berpikir kritis, dan berpikir kreatif (Aslan, 2015; Boholano, 2017; Dwyer et al., 2014; Kivunja, 2015; Urbani et al., 2017). Kemampuan ini yang menjadi sebuah focus dalam pendidikan biologi yang harus ditingkatkan. Pendidikan biologi sejatinya merupakan sebuah sarana untuk bisa mengantarkan siswa untuk bisa berpikir lebih tinggi dan memecahkan masalah yang dihadapi dalam kehidupan sehari-hari.

\section{KESIMPULAN}

Berdasarkan hasil penelitian dan pembahasan pada penelitian ini, maka dapat disimpulkan bahwa tingkat kevalidan LKPD berbasis Vee Mapping dengan revisi sebanyak 3 kali, memenuhi kategori sangat valid dengan skor rata-rata 3,86 sedangkan kepraktisan LKPD berbasis Vee Mapping yang dikembangkan berada pada kategori praktis dengan skor ratarata 3,51. Dengan demikian LKPD tersebut dapat digunakan dalam Pendidikan biologi abad 21.

\section{UCAPAN TERIMA KASIH}

Ucapan terima kasih kepada validator dan Kepala SMA Negeri 1 Takalar yang telah memberikan izin penelitian.

\section{REFERENSI}

Aslan, S. (2015). Is learning by teaching effective in gaining 21 st century skills? The views of pre-service science teachers. Kuram ve Uygulamada Egitim Bilimleri, 15(6), 1441-1457.

https://doi.org/10.12738/estp.2016.1.0019

Badan Standar Nasional Pendidikan. (2014). Instrumen Penilaian Buku Teks Pelajaran. BSNP. http://bsnpindonesia.org/2014/05/28/instrumenpenilaian-buku-teks-pelajaran-tahun2014/

Boholano, H. B. (2017). Smart social networking: 21st century teaching and 
learning skills. Research in Pedagogy, 7(1), 21-29. https://doi.org/10.17810/2015.45

Buzov, I. (2014). Social network sites as area for students' pro-environmental activities. Procedia - Social and Behavioral Sciences, 152, 1233-1236. https://doi.org/10.1016/j.sbspro.2014.09.3 04

Cubukcu, F. (2008). Enhancing vocabulary development and reading comprehension through metacognitive strategies. Issues in Educational Research, 18(1), 1-11.

Dwyer, C. P., Hogan, M. J., \& Stewart, I. (2014). An integrated critical thinking framework for the 21st century. Thinking Skills and Creativity, 12, 43-52. https://doi.org/10.1016/j.tsc.2013.12.004

Gowin, D. B., \& Alvarez, M. C. (2005). The art of educating with $V$ diagrams. Cambridge University Press.

Hemmerich, A. L., Hoepner, J. K., \& Samelson, V. M. (2015). Instructional Internships: Improving the teaching and learning experience for students, interns, and faculty. Journal of the Scholarship of Teaching and Learning, 15(3), 104. https://doi.org/10.14434/josotl.v15i3.1309 0

Kivunja, C. (2015). Teaching students to learn and to work well with 21 st century skills: Unpacking the career and life skills domain of the new learning paradigm. International Journal of Higher Education, 4(1), 1-11. https://doi.org/10.5430/ijhe.v4n1p1

Martin, F., \& Betrus, A. K. (2019). Digital media for learning: Theories, processes, and solutions. In Digital Media for Learning: Theories, Processes, and Solutions. Springer. https://doi.org/10.1007/978-3030-33120-7

Murphy, C., Bianchi, L., McCullagh, J., \& Kerr, K. (2013). Scaling up higher order thinking skills and personal capabilities in primary science: Theory-into-policy-into-practice. Thinking Skills and Creativity, 10, 173-
188.

https://doi.org/10.1016/j.tsc.2013.06.005

Nugraini, S. H., Choo, K. A., Hin, H. S., \& Hoon, T. S. (2013). Students' feedback of e-av biology website and the learning impact towards biology. Procedia - Social and Behavioral Sciences, 103, 860-869. https://doi.org/10.1016/j.sbspro.2013.10.4 08

Oncu, E. C. (2016). Improved creative thinkers in a class: a model of activity based tasks for improving university students creative thinking abilities. Educational Research and Reviews, 11(8), 517-522. https://doi.org/10.5897/ERR2015.2262

Paristiowati, M., Hadinugrahaningsih, T., Purwanto, A., \& Karyadi, P. A. (2019). Analysis of students' scientific literacy in contextual-flipped classroom learning on acid-base topic. Journal of Physics: Conference Series, 1156(1), 012026. https://doi.org/10.1088/17426596/1156/1/012026

Permana, F. H., \& Chamisijatin, L. (2019). Project-based learning through edmodo: improving critical thinking and histology concepts. Biosfer: Jurnal Pendidikan Biologi, 12(1), 58-69. https://doi.org/10.21009/biosferjpb.v12n1 $.58-69$

Ross, J. (2017). Speculative method in digital education research. Learning, Media and Technology, 42(2), 214-229. https://doi.org/10.1080/17439884.2016.11 60927

Sukiniarti. (2016). Improving Science Pedagogic Quality in Elementary School Using Process Skill Approach Can Motivate Student to Be Active in Learning. Journal of Education and Practice, 7(5), 150-157.

Tajudin, N. M., \& Chinnappan, M. (2016). The link between higher order thinking skills, representation and concepts in enhancing TIMSS tasks. International Journal of Instruction, 9(2), 199-214. https://doi.org/10.12973/iji.2016.9214a

Thiagarajan, S., Semmel, D. S., \& Semmel, M. I. 
(1974). Instructional development for training teachers of exceptional children. Indiana University.

Urbani, J. M., Truesdell, E., Urbani, J. M., Roshandel, S., Michaels, R., \& Truesdell, E. (2017). Developing and modeling 21stcentury skills with preservice teachers. Teacher Education Quarterly, 44(4), 2751.
Utami, W. S., Sumarmi, S., Ruja, I. N., \& Utaya, S. (2016). The Effectiveness of Geography Student Worksheet to Develop Learning Experiences for High School Students. Journal of Education and Learning, 5(3), 315-321.

https://doi.org/10.5539/jel.v5n3p315 